\title{
Analytical Process Evaluation of Biochemistry Laboratory by Using Six Sigma Method
}

\author{
Dilara Bal Topcu', [MD] \\ ORCID: 0000-0002-8731-0452 \\ Ahmet Ozsoy', [MD] \\ ORCID: 0000-0003-0718-3471 \\ Fatma Ucar', [MD] \\ ORCID: 0000-0001-7354-375X \\ Ali Yalcindag ${ }^{2},[\mathrm{MD}]$ \\ ORCID: 0000-0003-1846-9248 \\ Yesim Oztas ${ }^{3},[\mathrm{MD}, \mathrm{PhD}]$ \\ ORCID: 0000-0002-8638-9744
}

\begin{abstract}
'Ankara Akyurt State Hospital, Laboratory of Clinical Biochemistry, Ankara, Turkey.
\end{abstract}

${ }^{2}$ Diskapi Yildirim Beyazit Training and Research Hospital, Laboratory of Clinical Biochemistry, Ankara, Turkey.

${ }^{3}$ Hacettepe University, Faculty of Medicine, Department of Medical Biochemistry, Ankara, Turkey.

Corresponding Author: Dilara Bal Topcu Akyurt State Hospital, Clinical Biochemistry Laboratory, Akyurt, Ankara, Turkey.

Phone: +90 $3128443010 / 1061$

E-mail:drdilarabal@gmail.com

https://doi.org/10.32552/2021.ActaMedica.563

\section{n ABSTRACT Con}

Objectives: The primary purpose of medical laboratories is to provide the most accurate results appropriate to the patient's medical condition. Therefore, the reliability of each laboratory must be scientifically tested. Approximately $10 \%$ of laboratory errors occur in the analytical phase. In this study, we aimed to evaluate analytical process performances of 14 routinely assayed parameters according to Six Sigma methodology.

Materials and Methods: Mean, standard deviation and coefficient of variation were calculated from internal quality control data for 3 months from 14 routinely assayed parameters (albumin, alanine aminotransferase, aspartate aminotransferase, chloride, creatinine, glucose, HDL cholesterol, lactate dehydrogenase, potassium, total cholesterol, total protein, sodium, triglyceride and urea) in the laboratory (Roche Cobas c501). Bias was calculated using external quality control values for same months. Total error was also calculated. Acceptable total error was determined according to the Clinical Laboratory Improvement Amendments and Turkey criteria. Sigma values were calculated and divided into four groups; as <3 unacceptable; 3-4 suited for purpose; 4-6 acceptable; $>6$ world-class performance.

Results: According to the Clinical Laboratory Improvement Amendments and Turkey sigma assessment, first levels of chloride, total cholesterol, glucose and urea performance were unacceptable. Moreover according to the Clinical Laboratory Improvement Amendments sigma assessment, first levels of albumin, creatinine, total protein; and both levels of sodium, chloride and urea were unacceptable. Other tests were found to be suited for purpose, acceptable or world-class performance.

Conclusions: Sigma measurements should be routinely performed in laboratories for evaluating the analytical period performance of the laboratory. That will increase its quality via regulatory preventive actions. Our study allowed us to see and improve our measurement quality by determining the three-month periodic performance of our laboratory tests.

Keywords: Internal quality control, analytical performance assessment, six sigma methodology, total allowable error, westgard rules

Received: 4 February 2021, Accepted: 25 July 2021,

Published online: 5 September 2021 


\section{INTRODUCTION}

Clinical laboratory results are essential to diagnose and follow up the disease and they have obviously a great impact on the quality of health services. Also, laboratory tests provide guidance for approximately $80-90 \%$ of all diagnoses. Laboratory testing is a highly complex process in which laboratory errors were reported to occur with a frequency of $0.012-$ $0.6 \%$ for all test results [1].

While the clinical laboratories are playing a very critical role in clinical decision and medication, minimizing measurement errors should be the primary goal of clinical laboratories, to provide reliable, competent and accurate performances with a variety of defined scientific methods. These methods vary according to the stages of the total test process as pre-analytical, analytical and postanalytical. Laboratory errors are frequently seen in pre and post-analytical processes. Errors seen in the analytical phase represents the smallest proportion of overall test errors, about 7-13\% [2].

Quality control (QC) screening is a crucial process in the laboratory and ensures clinical diagnostic accuracy and quality of patient safety. QC monitoring can be done via three ways which are; internal quality control (IQC) program with the Levey-Jennings charts, the external quality control (EQC) programs, and Sigma metrics system which is newly acknowledged as analytical assessment method [3,4]. QC programs are not always sufficient for analytical stage evaluation. In addition to all these methods, a comprehensive and systematic evaluation is also required $[5,6]$.

Objective evaluation of performance can be achieved with the Six Sigma method. The sigma level of a process can be obtained by calculation using specific equations. The sigma value represent how often errors are probably to happen. If the sigma is a low value, the process will most likely produce errors. Ideal situation or world-class performance has at least 6 sigma value. this means that there were fewer than 3.4 errors per million products in this process [7].

Systematic error of a measurement is the difference from the actual concentration of the analyte, which can be positive or negative. Systematic error is expressed as a bias [8]. Precision (repeatability) is the power of an analytical method to produce the same result of repetitive measurements made from the same sample. It is being used to measure the random errors. Random error is expressed as coefficient of variation (CV). Total analytical error (TE) is the sum of random error and systematic error. Westgard et al. formulated TE \%= Bias \% + $(1.65 \times$ CV \%) [9]. Total allowable error (TEa) is the analytical quality specification that determines acceptable limits in a single test result [10]. The TEs of the laboratory for each test should be aimed to be lower than the target TEa values that they accept as criteria. Target TEa limits can be set in different ways. There are values set by organizations such as Clinical Laboratory Improvement Amendments (CLIA), besides each country can set its own national values [11]. TEa value for some tests has recently been determined by the Analytical Standardization and Harmonization Committee in our country (Turkey) [12]. Above mentioned sigma metrics calculate from TEa, CV, and bias [13].

In this study, we aimed to evaluate analytical performance of our laboratory according to TEa and Six Sigma methodology. The tests evaluated for this purpose; albumin (Alb), alanine aminotransferase (ALT), aspartate aminotransferase (AST), chloride $(\mathrm{Cl})$, total cholesterol (TChol), creatinine (Crea), glucose (Glu), HDL cholesterol (HDL-c), lactate dehydrogenase (LD), potassium (K), total protein $(\mathrm{TP})$, sodium $(\mathrm{Na})$, triglyceride $(\mathrm{Tg})$ and urea.

\section{MATERIALS and METHODS}

Mean, standard deviation (SD) and CV were calculated from period of 3 month from March 2020 to June 2020. A Cobas c501 device (Roche Diagnostics) was used to test assays: Alb, ALT, AST, $\mathrm{Cl}$, TChol, Crea, Glu, HDL-C, LD, K, TP, Na, Tg and urea in the laboratory. The method of each test was traceable to the reference method. Two levels of clinical chemistry controls, PreciControl ClinChem Multi 1 and 2 (Level 1: normal control, Level 2: pathological control) used for each parameter. Bias was determined from the same period's peer laboratory group of EQC data with this calculation: [Bias $\%=$ (our lab mean- mean of peer group) $\times$ $100 /$ mean] of peer group. The arithmetic average of bias was used to calculate sigma values. TE calculated via Bias \% + (1.65× CV \%) formula. TEa 
was determined according to the CLIA and Turkey (TR) criteria. CV of all assays were calculated from the 3 month IQC data as follows: CV \% = (SD $\times 100) /$ mean formula. Sigma values were calculated via (TEa \% - Bias \%)/ CV \% formula [14]. According to sigma levels groups divided into our groups; as $<3$ unacceptable; 3-4 suited for purpose; 4-6 acceptable; $>6$ world-class performance [15].

This study was approved by the Diskapi Yildirim Beyazit Training and Research Hospital Ethics Committee (06/07/2020-91/14).

\section{RESULTS}

Table 1 summarizes the calculated laboratory mean, CV \%, TE \%, TEa \%, Bias \% and sigma values depending on the CLIA and TR TEa. Table 2 and 3 summarize which Westgard rules could apply for improving future works based on depending CLIA and TR sigma values respectively $[3,16]$.

TE values of all tests were found under the TEa limits which depends on Turkey criteria while both levels of $\mathrm{Na}$ and first level of $\mathrm{Cl}$ tests'TE values were found higher than TEa which depends on CLIA criteria.

According to the CLIA and TR sigma assessment, first levels of $\mathrm{Cl}$, TChol, Glu and urea performance were unacceptable and also, according to the CLIA sigma assessment, first levels of Alb, Crea, TP and both levels of $\mathrm{Na}, \mathrm{Cl}$ and urea were unacceptable.

According to the TR and CLIA sigma assessment both levels of HDL-c were higher than 6 , have wordclass performance (Table 2-3).

According to the CLIA sigma assessment first level of Tg were higher than 6 , has word-class performance (Table 2).

According to CLIA sigma assessment both levels of $L D, A L T, K$ and second level of AST were between 4-6 (Table 2).

According to TR sigma assessment both levels of LD, ALT and second levels of Alb. AST, Crea, K, TP, Urea, Tg were between 4-6 (Table 3).

Other tests were found to be suited for purpose, between 3-4.

\section{DISCUSSION}

Tests with small sigma values are considered to exhibit low analytical performance. It reveals the necessity of evaluating the analytical process of these tests in detail, recommending the application of suitable Westgard Sigma rules. Another benefit of using sigma values is that it gives an opportunity to make adjustments in control applications [17].

Table 1. Calculated laboratory mean, CV \%, bias \%, TE \%, Tea \% and sigma values

\begin{tabular}{|c|c|c|c|c|c|c|c|c|c|c|c|c|c|c|c|}
\hline \multirow[t]{2}{*}{ Analyte } & \multicolumn{2}{|c|}{$\begin{array}{l}\text { Laboratory } \\
\text { mean }\end{array}$} & \multicolumn{2}{|c|}{ CV \% } & \multirow{2}{*}{$\begin{array}{c}\text { Bias } \\
\% \\
-\end{array}$} & \multicolumn{2}{|c|}{ TE \% } & \multicolumn{2}{|c|}{ TEa \% (CLIA) } & \multicolumn{2}{|c|}{$\begin{array}{c}\text { TEa \% } \\
\text { (Turkey) }\end{array}$} & \multicolumn{2}{|c|}{ Sigma (CLIA) } & \multicolumn{2}{|c|}{ Sigma (TR) } \\
\hline & $\mathrm{L}^{*}{ }^{*}$ & $\mathrm{~L} 2+$ & L1 & L 2 & & L1 & L2 & L1 & L2 & L1 & $\mathrm{L} 2$ & L1 & L2 & L1 & L2 \\
\hline Albumin (g/L) & 31.9 & 49.4 & 3.4 & 3.2 & 2.7 & 8.4 & 5.4 & 10.0 & 10.0 & 15.0 & 15.0 & 2.1 & 3.1 & 3.6 & 4.6 \\
\hline ALT (U/L) & 46.3 & 111.7 & 3.9 & 3.4 & 2.5 & 9.0 & 5.6 & 20.0 & 20.0 & 20.0 & 20.0 & 4.4 & 5.8 & 4.4 & 5.8 \\
\hline AST (U/L) & 50.9 & 150.7 & 4.4 & 4.5 & 3.7 & 10.9 & 7.5 & 20.0 & 20.0 & 20.0 & 20.0 & 3.7 & 4.4 & 3.7 & 4.4 \\
\hline $\mathrm{Cl}(\mathrm{mmol} / \mathrm{L})$ & 87.8 & 108.0 & 3.0 & 2.9 & 1.9 & 6.8 & 4.8 & 5.0 & 5.0 & 9.0 & 9.0 & 1.0 & 1.7 & 2.4 & 3.1 \\
\hline TChol (mg/dL) & 86.9 & 156.5 & 3.1 & 3.0 & 2.6 & 7.7 & 5.0 & 10.0 & 10.0 & 11.0 & 11.0 & 2.4 & 3.3 & 2.7 & 3.6 \\
\hline Crea (mg/dL) & 1.1 & 3.9 & 5.4 & 4.3 & 4.0 & 12.9 & 7.2 & 15.0 & 15.0 & 20.0 & 20.0 & 2.0 & 3.5 & 3.0 & 4.6 \\
\hline Glu (mg/dL) & 101.7 & 230.8 & 3.6 & 3.4 & 1.6 & 7.5 & 5.6 & 10.0 & 10.0 & 11.0 & 11.0 & 2.3 & 3.0 & 2.6 & 3.3 \\
\hline $\mathrm{HDL}-\mathrm{C}(\mathrm{mg} / \mathrm{dL})$ & 26.4 & 66.3 & 2.5 & 2.7 & 3.1 & 7.3 & 4.4 & 30.0 & 30.0 & 30.0 & 30.0 & 10.8 & 11.2 & 10.8 & 11.2 \\
\hline LD (U/L) & 167.2 & 313.9 & 3.3 & 3.5 & 2.1 & 7.5 & 5.7 & 20.0 & 20.0 & 21.0 & 21.0 & 5.4 & 5.8 & 5.7 & 6.0 \\
\hline $\mathrm{K}(\mathrm{mmol} / \mathrm{L})$ & 3.6 & 6.9 & 2.0 & 2.0 & 1.4 & 4.6 & 3.3 & 13.0 & 8.3 & 9.0 & 9.0 & 5.9 & 4.1 & 3.9 & 4.4 \\
\hline TP (g/L) & 48.7 & 75.9 & 3.0 & 3.1 & 3.1 & 8.0 & 5.2 & 10.0 & 10.0 & 15.0 & 15.0 & 2.3 & 3.2 & 4.0 & 4.8 \\
\hline $\mathrm{Na}(\mathrm{mmol} / \mathrm{L})$ & 112.8 & 137.1 & 2.0 & 2.3 & 1.2 & 4.6 & 3.7 & 2.9 & 3.2 & 9.0 & 9.0 & 0.8 & 1.4 & 3.8 & 4.0 \\
\hline $\mathrm{Tg}(\mathrm{mg} / \mathrm{dL})$ & 118.0 & 225.0 & 3.1 & 2.9 & 3.1 & 8.3 & 4.7 & 25.0 & 25.0 & 15.0 & 15.0 & 7.0 & 8.7 & 3.8 & 5.2 \\
\hline Urea (mg/dL) & 38.6 & 113.6 & 3.4 & 3.2 & 5.9 & 11.4 & 5.3 & 12.2 & 9.0 & 15.0 & 15.0 & 1.9 & 2.8 & 2.7 & 4.7 \\
\hline
\end{tabular}


Table 2. Sigma values depending on CLIA assessment and recommended internal quality control rules

\begin{tabular}{|c|c|c|c|c|}
\hline $\begin{array}{l}\text { Sigma metrics } \\
\text { (CLIA) }\end{array}$ & Parameters & Levels of control & Assay performance & Westgard Rules \\
\hline$>6$ & $\begin{array}{l}\text { HDL-c, } \mathrm{Tg} \\
\text { HDL-c, } T g\end{array}$ & $\begin{array}{l}1 \\
2\end{array}$ & World Class & $\begin{array}{l}1_{3 \mathrm{~s}} \\
2 \text { Levels, } 1 \text { Times per day }\end{array}$ \\
\hline $4-6$ & $\begin{array}{l}\text { ALT, LD, K } \\
\text { ALT, AST, LD, K }\end{array}$ & $\begin{array}{l}1 \\
2\end{array}$ & Acceptable & $\begin{array}{l}1_{2.55} \\
2 \text { Levels, } 1 \text { Times per day }\end{array}$ \\
\hline $3-4$ & $\begin{array}{l}\text { AST } \\
\text { Alb, TChol, Glu, Crea TP }\end{array}$ & $\begin{array}{l}1 \\
2\end{array}$ & Suited for purpose & $\begin{array}{l}1_{35} / 2_{25} / R_{45} / 4_{15} \\
2 \text { Levels, } 2 \text { Times per day }\end{array}$ \\
\hline$<3$ & $\begin{array}{l}\mathrm{Cl} \text {, TChol, } \mathrm{Na} \text {, Urea, Alb, Crea, TP, Glu } \\
\mathrm{Cl} \text {, Na, Urea }\end{array}$ & $\begin{array}{l}1 \\
2\end{array}$ & Unacceptable & $\begin{array}{l}1_{35} / 2_{25} / R_{45} / 4_{15} \\
3 \text { Levels, } 2 \text { Times per day }\end{array}$ \\
\hline
\end{tabular}

Table 3. Sigma values depending on TR assessment and recommended internal quality control rules

\begin{tabular}{|c|c|c|c|c|}
\hline $\begin{array}{l}\text { Sigma metrics } \\
\text { (TR) }\end{array}$ & Parameters & Levels of control & Assay performance & Westgard Rules \\
\hline$>6$ & $\begin{array}{l}\text { HDL-C } \\
\text { HDL-C }\end{array}$ & $\begin{array}{l}1 \\
2\end{array}$ & World Class & $\begin{array}{l}1_{3 \mathrm{~s}} \\
2 \text { Levels, } 1 \text { Times per day }\end{array}$ \\
\hline $4-6$ & $\begin{array}{l}\text { ALT, LD } \\
\text { Alb, ALT, AST, LD, K, TP, Crea,Tg, Urea }\end{array}$ & $\begin{array}{l}1 \\
2\end{array}$ & Acceptable & $\begin{array}{l}1_{2.55} \\
2 \text { Levels, } 1 \text { Times per day }\end{array}$ \\
\hline $3-4$ & $\begin{array}{l}\text { Alb, AST, Cre, } \mathrm{Na}, \mathrm{Tg}, \mathrm{K} \\
\text { Glu, Cl, TChol Na }\end{array}$ & $\begin{array}{l}1 \\
2\end{array}$ & Suited for purpose & $\begin{array}{l}1_{3 S} / 2_{2 S} / R_{45} / 4_{15} \\
2 \text { Levels, } 2 \text { Times per day }\end{array}$ \\
\hline$<3$ & $\begin{array}{l}\text { Cl, TChol, Glu, Urea } \\
-\end{array}$ & $\begin{array}{l}1 \\
2\end{array}$ & Unacceptable & $\begin{array}{l}1_{35} / 2_{25} / R_{45} / 4_{15} \\
3 \text { Levels, } 2 \text { Times per day }\end{array}$ \\
\hline
\end{tabular}

In this study we analyzed test results for 14 parameters in a period of 3 months. Although our internal quality control values, which we routinely apply to these parameters, seem appropriate but when sigma analysis was performed, it was revealed that the performance of some tests was actually low.

Tests with sigma values depending on CLIA assessment, below 3 are at a high rate in our study but on the other hand we found TE values of all tests in appropriate TEa limits except both levels of $\mathrm{Na}$ and $\mathrm{Cl}$ which depend on CLIA criteria.

According to the CLIA and TR sigma assessment, first levels of $\mathrm{Cl}$, TChol, Glu and urea performance were unacceptable and also, according to the CLIA sigma assessment, first levels of Alb, Crea, TP and both levels of $\mathrm{Na}, \mathrm{Cl}$ and urea were unacceptable.

We should rigorously follow applied QC Westgard multi rules and pay extra attention to these tests. Method performance must be reformed primarily for these tests and three levels of QC should be taken twice a day with applying $13 \mathrm{~s} / 22 \mathrm{~s} / \mathrm{R} 4 \mathrm{~s} / 41 \mathrm{~s}$ rule (Table 2 , Table 3 ).
Parameters with sigma values between 3 and 4, two levels of QC with a $13 \mathrm{~s} / 22 \mathrm{~s} / \mathrm{R} 4 \mathrm{~s} / 41 \mathrm{~s}$ rule should be taken twice a day (Table 2, Table 3).

Parameters have sigma values in the range of 4 to 6 , two levels of QC with a 12.5 s rule should be taken twice a day (Table 2, Table 3).

Tests with sigma values higher than 6 required only a single rejection rule of $13 \mathrm{~s}$, with two control measurements of each level in a run. In this way, the number of unnecessary IQC assessments can be reduced and thus cost, labor and time can be saved.

Gulbahar et al. [18] who used four different biochemical analyzers, a sigma value lower than 3 was observed mostly for tests urea, $\mathrm{Na}$, and $\mathrm{K}$ using the TEa values of CLIA. Korkmaz [19] calculated sigma metrics for 17 assays on the Beckman Coulter UniCel DxC 800 analyzer using CLIA TEa targets and showed that sigma levels for Glu (both levels), TP (level 1) amilase (level 2) tests were lower than 3. Nanda et al. [13] calculated sigma values less than 3 for urea, TP, Alb, TChol and Cl in Cobas Integra auto analyzer. 
Also our results are comparable to the results of Mao et al. for urea, $\mathrm{Na}$, and $\mathrm{Cl}$ which were below 3 sigma. However they found differently sigma metrics between 3-6 for Glu and TChol from our study [17]. In a study by Verma et al. sigma values of Glu, urea and TChol were $<3$ [20]. In these studies TEa for calculating the sigma metrics are taken from the guidelines of CLIA like us.

Sigma levels of some analytes showed variations among different studies. This situation can be explained by various reasons; using the different types of analyzers, reagents, and QC materials, selecting various source of the TEa targets and using different algorithms to calculate the bias and $\mathrm{CV}$, which might affect the sigma values [21].

Six Sigma is a statistical measure, which firstly discovered and used in non-healthcare industry to achieve the highest level of quality. In nonhealthcare ventures, sigma level under 3 is regard as suboptimal performance. In health care the sigma performance is not recognized well however, performance level of 2 to 3 has been quoted in most assessments [22]. These results show that analytic quality is still a major problem when evaluated on the sigma scale [3].

TEa expresses the degree of error which can be tolerated in a test result. TEa based on biological variations and is acknowledged concept in laboratory medicine. CLIA values are more stringent than TR values. Utilizing more relaxed TEa values will yield better sigma values [22].
EQC assessment results should compare with reference method goal values. Using reference materials or comparison with reference methods are ideal ways. But because of financial reasons we could not perform this [23]. We calculated bias from EQC data which is the most used method in literature. Utilization of Six Sigma methodology should be easy, quick, and reliable.

The Six Sigma methodology gives us the opportunity to create our own QC strategy and conduct self-assessment. It can be very beneficial to apply this metrics for produce accurate test results into our laboratory.

\section{CONCLUSION}

Sigma measurements should be routinely performed in laboratories to assess the analytical period performance of the laboratory and improve its quality through regulatory preventive actions. Our study allowed us to see and improve our measurement quality by determining the 3-month periodic performance of our laboratory tests.

\section{CONFLICT Of INTEREST STATEMENT}

Authors declare that they have no conflict of interest and financial support for this study.
[1] O'Kane M. The reporting, classification and grading of quality failures in the medical laboratory. Clinica chimica acta; international journal of clinical chemistry. 2009;404(1):28-31.

[2] Plebani M. Errors in clinical laboratories or errors in laboratory medicine? Clinical chemistry and laboratory medicine. 2006;44(6):750-759.

[3] Westgard JO, Westgard SA. The quality of laboratory testing today: an assessment of sigma metrics for analytic quality using performance data from proficiency testing surveys and the CLIA criteria for acceptable performance. American journal of clinical pathology. 2006;125(3):343354.
[4] Tzortzopoulos A, Raftopoulos V, Talias MA. Performance characteristics of automated clinical chemistry analyzers using commercial assay reagents contributing to quality assurance and clinical decision in a hospital laboratory. Scandinavian journal of clinical and laboratory investigation. 2020;80(1):46-54.

[5] Westgard JO, Burnett RW, Bowers GN. Quality management science in clinical chemistry: a dynamic framework for continuous improvement of quality. Clinical chemistry. 1990;36(10):1712-1716.

[6] Iqbal S, Mustansar T. Application of Sigma Metrics Analysis for the Assessment and Modification of Quality Control Program in the Clinical Chemistry Laboratory of a Tertiary Care Hospital. Indian J Clin Biochem. 2017;32(1):106-109. 
[7] Nevalainen D, Berte L, Kraft C, et al. Evaluating laboratory performance on quality indicators with the six sigma scale. Archives of pathology \& laboratory medicine. 2000;124(4):516-519.

[8] Burtis CA, Bruns DE. Selection and Analytical Evaluation of Methods - With Statistical Techniques. In: Tietz Fundamentals of Clinical Chemistry and Molecular Diagnostics. Seventh ed. USA: Saunders; 2015.

[9] https://www.aacc.org/cln/articles/2013/september/totalanalytic-error. Accessed 17th March, 2018.

[10] Westgard JO, Carey RN, Wold S. Criteria for judging precision and accuracy in method development and evaluation. Clinical chemistry. 1974;20(7):825-833.

[11] Burtis CA, Bruns DE, Ashwood ER. Tietz Textbook of Clinical Chemistry And Molecular Diagnostics In: 5th ed.: Saunders, an imprint of Elsevier Inc.; 2012.

[12] T.C. Saglik Bakanligi Saglik Hizmetleri Genel Müdürlügü Tibbi Laboratuvar Hizmetleri Daire Baskanligi; 95966346 numarali ve İzin Verilen Toplam Hata Sınıları konulu, 13/10/2016 tarihli genelge. http://www.laboratuvar.saglik. gov.tr/Eklenti/2581,genelge-201618izin-verilen-toplamhata-sinirlaripdf.pdf?0. Accessed 10 December, 2016.

[13] Nanda SK, Ray L. Quantitative application of sigma metrics in medical biochemistry. Journal of clinical and diagnostic research : JCDR. 2013;7(12):2689-2691.

[14] Coskun A. Six Sigma and laboratory consultation. Clinical chemistry and laboratory medicine. 2007;45(1):121-123.

[15] Westgard JO, Seehafer JJ, Barry PL. European specifications for imprecision and inaccuracy compared with operating specifications that assure the quality required by US CLIA proficiency-testing criteria. Clinical chemistry. 1994;40(7 Pt 1):1228-1232.
[16] Westgard JO, Westgard SA. Quality control review: implementing a scientifically based quality control system. Annals of clinical biochemistry. 2016;53(Pt 1):32-50.

[17] Mao X, Shao J, Zhang B, et al. Evaluating analytical quality in clinical biochemistry laboratory using Six Sigma. Biochem Med (Zagreb). 2018;28(2):020904-020904.

[18] Gülbahar Ö, Kocabıyık M, Çıracı MZ, et al. The use of six sigma methodology to evaluate the analytical performances of clinical chemistry analyzers. Turkish Journal of Biochemistry. 2018;43(1):1-8.

[19] Korkmaz S. Analitik Evre Performansının Altı Sigma Metodu Kullanılarak Değerlendirilmesi. Journal of Turkish Clinical Biochemistry. 2020;17(3):126-133.

[20] Verma M, Dahiya K, Ghalaut VS, et al. Assessment of quality control system by sigma metrics and quality goal index ratio: A roadmap towards preparation for NABL. World journal of methodology. 2018;8(3):44-50.

[21] Zhou B, Wu Y, He H, et al. Practical application of Six Sigma management in analytical biochemistry processes in clinical settings. J Clin Lab Anal. 2020;34(1):e23126.

[22] Shaikh MS, Moiz B. Analytical performance evaluation of a high-volume hematology laboratory utilizing sigma metrics as standard of excellence. International journal of laboratory hematology. 2016;38(2):193-197.

[23] Friedecky B, Kratochvila J, Budina M. Why do different EQA schemes have apparently different limits of acceptability? Clinical chemistry and laboratory medicine. 2011;49(4):743-745. 